\title{
IMAGES OF LISCH NODULES ACROSS THE SPECTRUM
}

\author{
NICOLA K. RAGGE ${ }^{1}$, RENA E. FALK ${ }^{2}$, WARREN E. COHEN ${ }^{2}$ and A. LINN MURPHREE ${ }^{1}$ \\ Los Angeles, USA
}

\begin{abstract}
SUMMARY
The presence of melanocytic hamartomas on the iris, known eponymously as Lisch nodules, is highly characteristic of neurofibromatosis type 1 (NF1). Early recognition of NF1 is vital for optimal detection of associated tumours and for genetic counselling of family members. Although the iris nodules are probably not visible at birth, their prevalence in patients with NF1 gradually increases from birth to about $50 \%$ of 5 -year-olds, $75 \%$ of 15-year-olds and 95-100\% of adults over the age of 30. Iris hamartomas in NF1 are elevated, pale brown lesions that vary in appearance depending on the underlying colour of the iris. Colour illustrations are shown in this article, enabling the clinician readily to differentiate hamartomas from other iris lesions.
\end{abstract}

In 1937 Lisch $^{1}$ published his now classic paper which emphasised the association between iris nodules and von Recklinghausen's neurofibromatosis (now neurofibromatosis type 1 or NF1). Following this article these iris lesions came to be known eponymously as Lisch nodules. Almost 50 years later Lewis and Riccardi ${ }^{2}$ described the high prevalence of these nodules in NF1 and focused medical attention on their diagnostic importance.

Although some ophthalmologists have been credited with earlier descriptions of these iris nodules, ${ }^{1}$ surprisingly few of these turn out to be the genuine iris lesions associated with NF1. Instead, many of the earlier authors appear to be describing a different condition, that of iris elevations associated with melanosis oculi or iris heterochromia. ${ }^{3-6}$ These iris lesions are quite different: regularly spaced small elevations described variously as 'golf-ball iris' or 'goose-skin' by Coats ${ }^{4}$ (see Fig. 1), or a 'field of stubble or a deforested landscape where only the stumps of trees remain' by Friedenwald and Friedenwald. ${ }^{6} \mathrm{Had}$ the last authors been describing true iris nodules as seen in $\mathrm{NF} 1$, from shape alone they would perhaps have referred

From: ${ }^{1}$ Division of Ophthalmology and ${ }^{2}$ Division of Medical Genetics, Children's Hospital, Los Angeles, University of Southern California, California, USA.

Correspondence to: Miss Nicola K. Ragge, MA, MRCP, FCOphth, Mailstop 88, Childrens Hospital Los Angeles, 4650 Sunset Boulevard, Los Angeles CA 90027, USA. to the rounded tops of deciduous trees, rather than their stumps!

At an Ophthalmological Society of the United Kingdom meeting in the early 1900 s, Snell ${ }^{7}$ presented what may have been the earliest description of true iris nodules associated with NF1. He described 'irregular yellowish markings' near the pupil margin of the iris in a patient with a plexiform neurofibroma of the orbit and associated buphthalmos. In 1913 Fuchs $^{8}$ published a description and histological illustrations of the iris nodules. Five years later Waardenburg ${ }^{9}$ also described small wart-like growths on the iris, but he did not illustrate them or directly link them with neurofibromatosis at that time.

In 1930 Goldstein and Wexler ${ }^{10}$ made the association between melanotic nodules on the iris and neurofibromatosis and provided histopathological illustrations. Their patient had bilateral diffuse corneal infiltration, which prevented them from identifying the iris nodules prior to microscopic examination at autopsy. Following this, Gabriélidès ${ }^{11}$ noticed the association in 1931 in a single detailed case report. Kurz ${ }^{12}$ presented a case of Lisch nodules in association with neurofibromatosis at a Czech congress in 1932. In the 1932 Doyne Memorial Lecture, Van der Hoeve ${ }^{13}$ made the association between neurofibromatosis and iris 'tumours' in 3 separate patients with neurofibromatosis, including 2 from Waardenburg, but did not illustrate his article. Then in 1935, two years before Lisch's paper, Sakurai ${ }^{14}$ in Japan published a beautifully illustrated paper linking characteristic iris nodules with von Recklinghausen's neurofibromatosis, complete with three unequivocal pictures of the iris appearances (see Fig. 2). Two years later Lisch published his famous paper with one illustration in the German literature (see Fig. 3).

\section{THE APPEARANCES OF LISCH NODULES}

Lisch nodules occur in all racial types. They vary in size and number from, in extreme cases, a single 'salt-grain' on one iris alone, barely visible by slit lamp examination, to prolific, sometimes innumerable or very large nodules, even $2 \mathrm{~mm}$ in diameter. Fortunately in most adults, except in very dark irides, they are easily visible either with the 

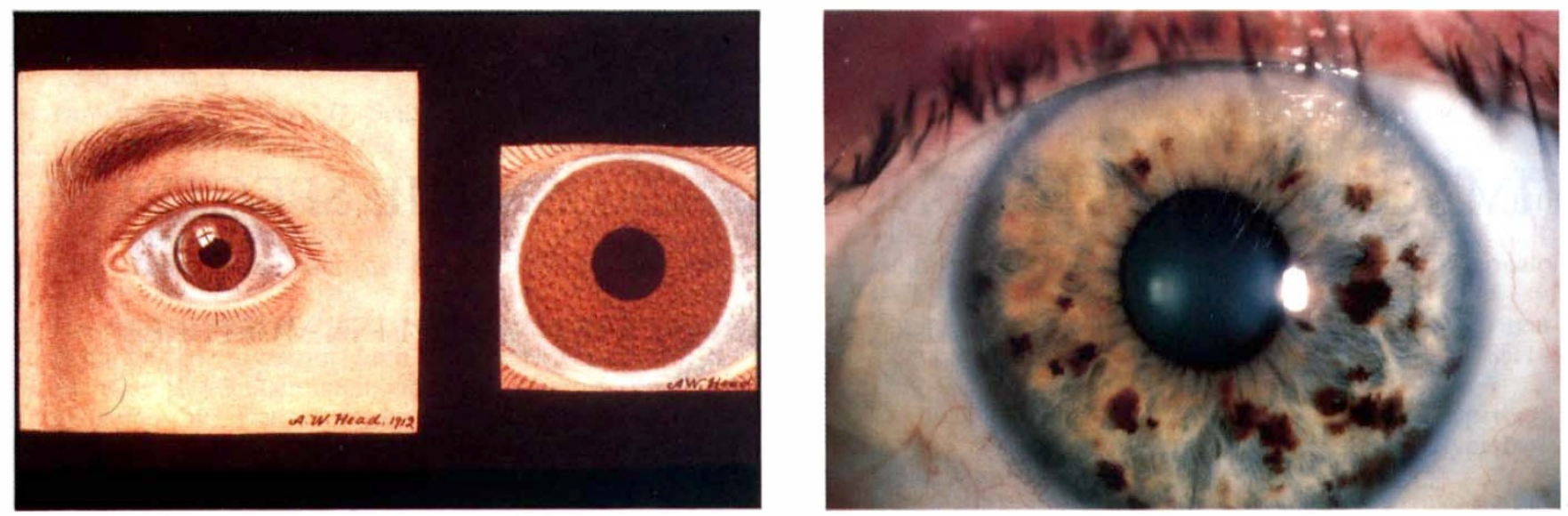

Fig. 1. Differential diagnosis of Lisch nodules. Left: The original illustration by Coats ${ }^{4}$ as a differential diagnosis of Lisch nodules, showing iris lesions associated with melanosis oculi. Right: Multiple iris naevi.

naked eye or with the aid of an illuminated magnifying glass. On the other hand, declaring their absence requires slit lamp examination.

Lisch nodules vary widely in appearance depending on the background colour of the iris (see Fig. 4). In all eyes they have an elevated, fleshy appearance, best appreciated by tangential broad beam illumination. In blue and green irides they appear pale-to-medium brown with feathery margins, and in dark brown irides they are cream coloured, dome-shaped and extremely well defined. The nodules are distributed in a random fashion on the anterior surface of the iris and occasionally just in the angle, when they can be viewed gonioscopically. Although Lisch nodules have a highly characteristic appearance, there are a few iris conditions that may be similar (Table I).

\section{HISTOLOGY AND ELECTRON MICROSCOPY OF LISCH NODULES}

Fuchs in 1918 and Goldstein and Wexler ${ }^{10}$ in 1930 pub-

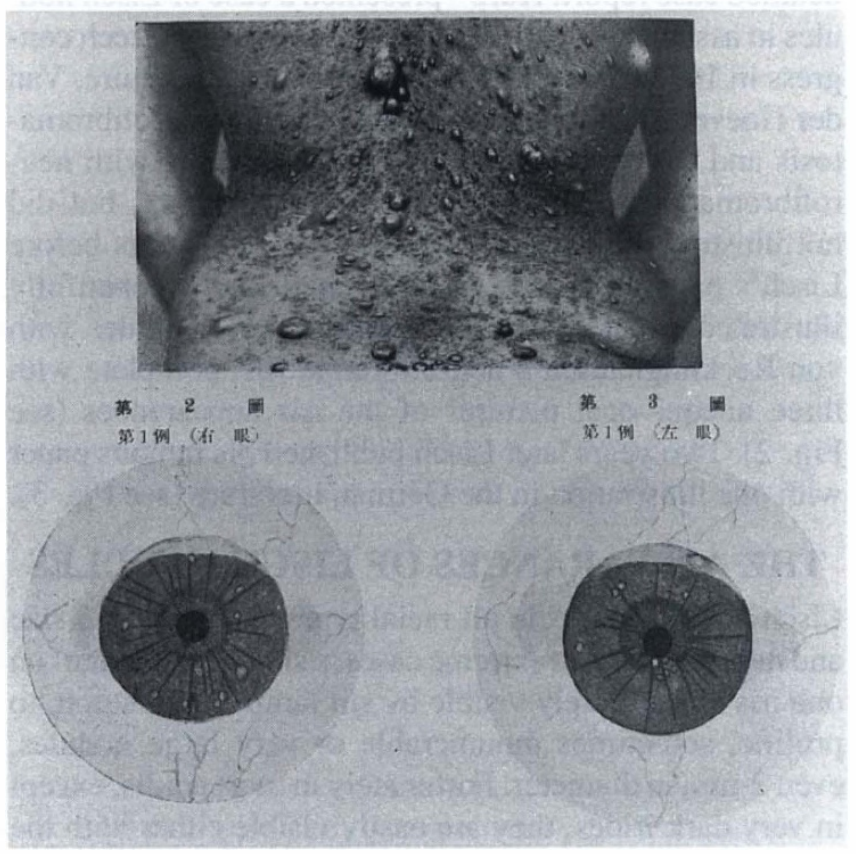

Fig. 2. The original illustration by Sakurai. ${ }^{14}$ lished the early light microscopic appearances of the iris nodules. About 50 years later Perry and Font ${ }^{15}$ presented electron microscopic findings of Lisch nodules from an iridectomy specimen in an NF1 patient. They confirmed that Lisch nodules were melanocytic hamartomas and were not derived from Schwann cells. In 1991 Williamson and colleagues ${ }^{16}$ further determined by light and electron microscopy that Lisch nodules consist of a condensation of spindle cells on the anterior iris surface and are of melanocytic origin. They also found that when they are pigmented, this is because an underlying stromal naevus is present.

\section{PREVALENCE OF LISCH NODULES}

We combined data from six large studies ${ }^{2,17-22}$ of the prevalence of Lisch nodules in different age groups. The techniques and advantages of meta-analysis for the purposes of integrating results have been recently reviewed. ${ }^{23,24}$ Each study examined between 30 and 167 patients with NF1 by NIH diagnostic criteria. The total number of patients analysed was 417 , with an overall age range for all the studies from 5 weeks to 83 years old. We obtained the raw data from one study. ${ }^{20}$ In the other studies, prevalence rates were expressed in narrow age ranges, for example 1-2 years, so that the data could be combined, especially in youth where prevalence changes rapidly with age. ${ }^{17.18,21}$ Sizes of groups were standardised by adjusting the age range limits. In adulthood, prevalence values were steady over a very large age range. For example several

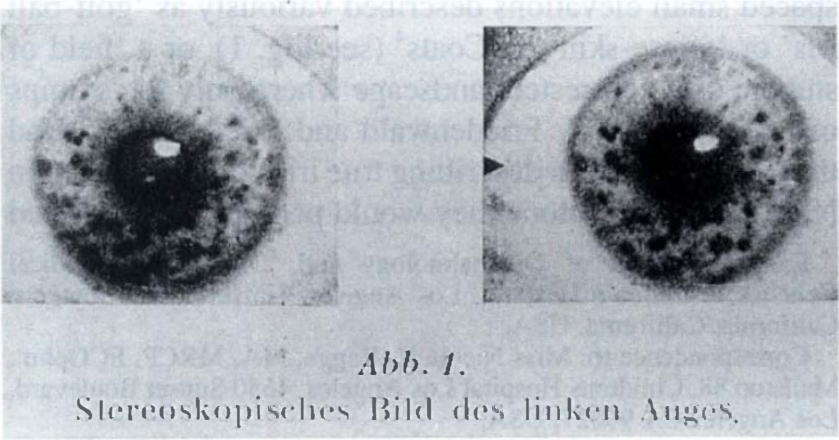

Fig. 3. The illustration in Lisch's original article. 
Table I. Differential diagnosis of Lisch nodules

\section{Iris naevi}

Multiple

Iridocorneal endothelial syndromes

Iris mammillations associated with melanosis oculi

Inflammatory nodules

Granulomatous uveitis, e.g. sarcoidosis (Koeppe and Busacca

nodules), tuberculosis

Roseolae and gumma in syphilis

Iris pearls in leprosy

Tumours

Iris cyst

Iris melanoma

Tapioca melanoma

Retinoblastoma (pseudogranulomatous uveitis)

studies indicated a prevalence of $100 \%$ in adults: over 12 years of age,$^{17,18}$ over 30 years of age ${ }^{20,22}$ or over 40 years of age. ${ }^{2}$ In one paper, ${ }^{22}$ all patients aged $21-35$ years had Lisch nodules, but in 1 of the 8 patients aged over 35 they were not detectable. In another study, only 1 patient of 40 over the age of 30 years failed to show any Lisch nodules. In neither study was gonioscopy performed to exclude the presence of Lisch nodules in the angle alone.

The average prevalence was obtained for the different age groups. The median age of each group was used to plot the final point. The size of the groups was indicated by the diameter of a circle drawn around the point. From the graph of pooled data an approximate prevalence can be determined for different age groups.

The prevalence of Lisch nodules increases semilogarithmically with age $\left(r^{2}=0.89\right)$. From this, it is likely that Lisch nodules are difficult to detect at birth. However, they are present in approximately $33 \%$ of NF1 patients aged 2.5 years, almost $50 \%$ of 5-year-olds, approximately $75 \%$ of 15 -year-olds and $90 \%$ of 25 -year-olds. Between $95 \%$ and $100 \%$ of those with NF1 over the age of 30 have Lisch nodules. Unlike neurofibromas, there is no acceleration in the rate of appearance of these nodules associated with puberty. $^{2}$

\section{DISCUSSION}

Lisch nodules are melanocytic iris hamartomas, ${ }^{10,15,16}$ and in keeping with many other pathological features of NF1 they are derived from neural crest tissue. Their importance, only recently realised, ${ }^{2}$ cannot be emphasised too strongly. Prompt and reliable diagnosis of NF1 is critical

Table II. NIH inclusive diagnostic criteria for $\mathrm{NF} 1^{32}$

The diagnostic criteria are met if a person has two or more of the following:

Six or more café au lait macules $>5 \mathrm{~mm}$ in diameter pre-pubertally and $>15 \mathrm{~mm}$ diameter post-pubertally

Two or more neurofibromas of any type or one plexiform neurofibroma

Axillary or inguinal freckling

Optic glioma

Two or more Lisch nodules

A distinctive osseous lesion such as sphenoid dysplasia or thinning of long bone cortex with or without pseudarthrosis

A first-degree relative with NF1
Table III. Ocular findings in neurofibromatosis type 1

Presumed neurofibromas of conjunctiva

Prominent corneal nerves

Posterior embryotoxon

Lisch nodules

Congenital ectropion uveae

Heterochromia iridis

Neurofibroma of ciliary nerves

Plexiform neurofibroma of eyelid and orbit

Glaucoma

Angle anomalies

Choroidal hamartoma

Chorioretinal scar

Congenital hypertrophy of the retinal pigment epithelium

Myelinated nerve fibres

Astrocytic hamartoma

Optic nerve head glioma

Optic glioma

Strabismus

for early detection of associated tumours and genetic counselling of family members. Until a useful genetic test is developed, they continue to be an extremely important diagnostic sign.

In the presence of other dragnostic features of NF1 or a positive family history, Lisch nodules confirm the diagnosis. In the absence of other signs of NF1, their presence is highly suggestive of NF1. Although the NIH diagnostic criteria (Table II) include two or more Lisch nodules, a single nodule in only one eye can contribute to the diagnosis in the presence of other signs or family history of NF1. A summary of other ophthalmic manifestations of NF1 is shown in Table III. In the paediatric population, although café au lait patches are the most common sign, Lisch nodules, if present, are highly specific for the diagnosis (more than axillary freckling or neurofibromas) and rarely may be the only sign of NF1. ${ }^{27}$

Lisch nodules are present in almost $100 \%$ of adults with NF1 over the age of 35 years. The prevalence increases gradually from 0 at birth, reaching $75 \%$ in the mid-teens and $90 \%$ by the mid-twenties. The nodules also occur in patients with no other features of NF1 (predecessors of affected patients with $\mathrm{NF} 1^{27}$ ), or in otherwise unaffected relatives of patients with $\mathrm{NF}^{25}$ (Table IV). Furthermore, patients with Watson's syndrome (an allelic variant of NF1 characterised by café au lait patches, mental retardation and pulmonary stenosis ${ }^{28}$ have these nodules. In patients with segmental neurofibromatosis, Lisch nodules may occur on the same side as the other manifestations. ${ }^{29}$ Very rarely, and rather surprisingly in view of the different chromosome assignment of this disease, Lisch nodules have been described in isolated cases of NF2. ${ }^{30,31}$

Table IV. Categories of patients with Lisch nodules

Affected patients with NF1

Otherwise unaffected patients with $N F 1^{25}$

Patients with Watson's syndrome (allelic variant of NF1

characterised by café au lait patches, mental retardation and pulmonary stenosis) ${ }^{28}$

Patients with segmental neurofibromatosis ipsilateral to the other manifestations ${ }^{29}$

Very rare, isolated cases of $\mathrm{NF} 2^{30,31}$ 

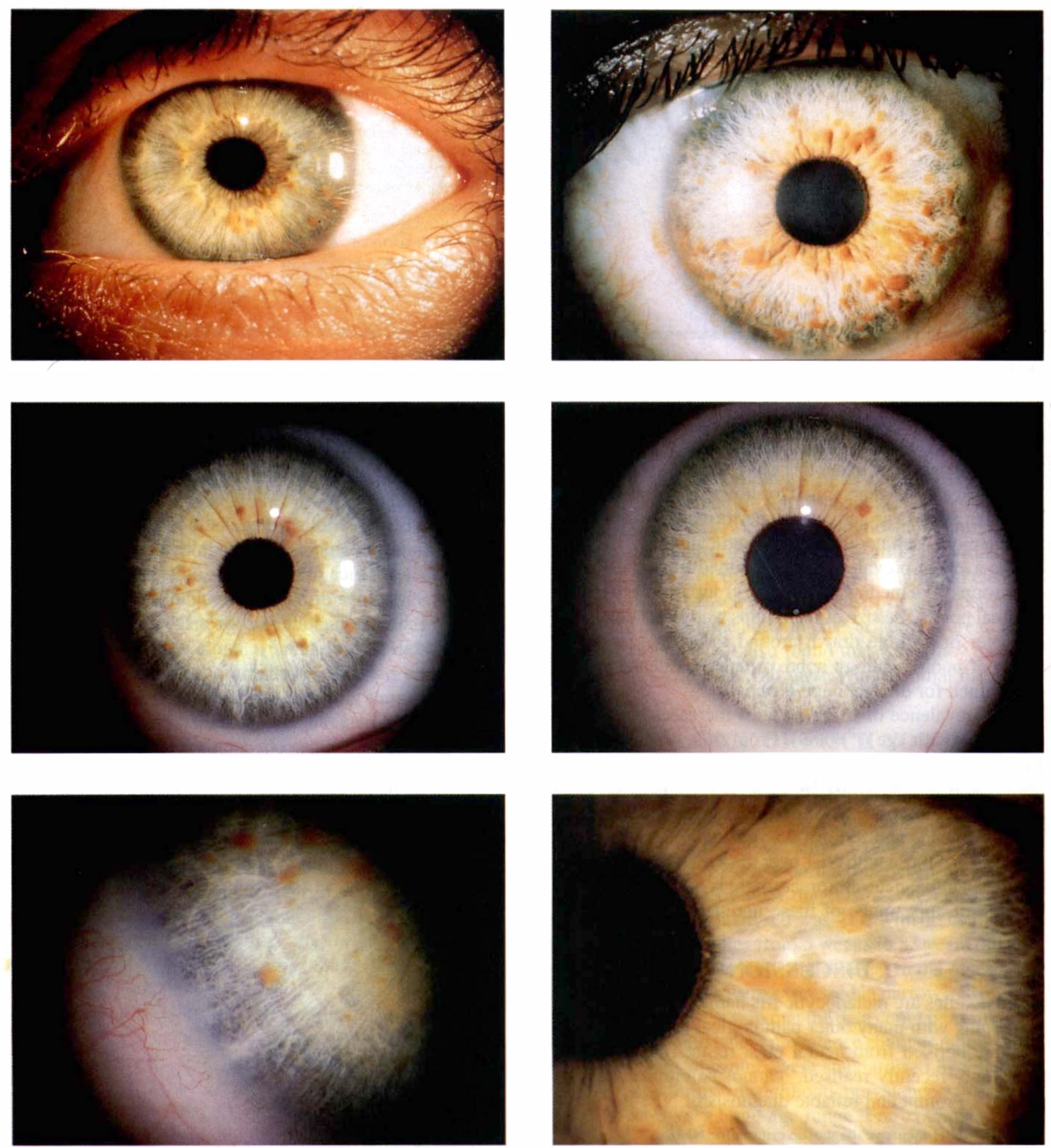

Fig. 4. The spectrum of appearances of Lisch nodules in different coloured irides.

The universal finding of Lisch nodules in NF1 and in apparently otherwise unaffected family member ${ }^{25}$ is of especial interest now that the gene is cloned. ${ }^{26}$ The gene for NF1 is situated on the long arm of chromosome 17 and is one of the largest genes to code for a single disease in man, with a protein product, 'neurofibromin', comprising 2818 amino acids. The function of the gene product is a subject under intense study at present. Exactly how this gene product will relate to the multiple and diverse manifestations of NF1 in different tissues remains to be seen.

\section{CONCLUSION}

The purpose of our paper is to provide the ophthalmologist with a firm basis for the identification of Lisch nodules in NF1 and some indication of their prevalence in different age groups. The ophthalmologist can then provide critical diagnostic information to other specialists caring for 

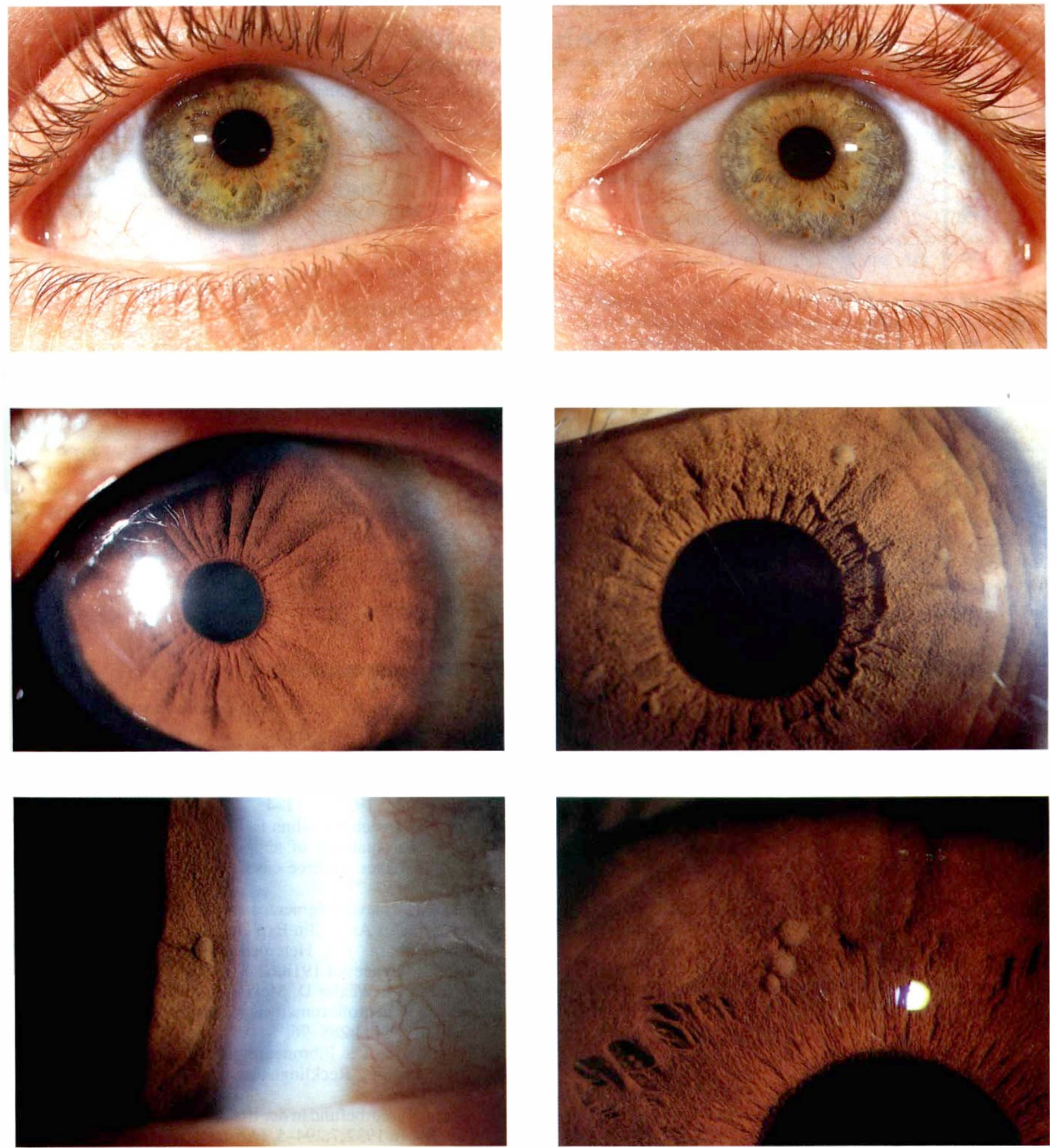

Fig. 4. (Continued).

patients with this diversely manifest disease. Use of an illuminated magnifying glass could assist the ophthalmic and non-ophthalmic specialist in the initial screening for these nodules, especially on young children and where no specialised equipment is available. However, in difficult cases slit lamp examination is required, including gonioscopy to answer the question definitively for the purposes of exclusion. Furthermore, in view of the other ocular manifestations seen in NF1, a full ophthalmic evaluation is recommended.

Finally we propose that Tsuya Sakurai, a Japanese physician, be given credit for her detailed and well-illustrated description of iris lesions and von Recklinghausen neurofibromatosis. We wish to rename them SakuraiLisch nodules. in her honour.

The authors gratefully acknowledge helpful discussion with Professor W. F. Hoyt, University of California, San Francisco, and Dr. V. Riccardi, La Crescenta, California, and wish to thank Ben Szirth PAV, Diana Wong and Wendy McNamara of the ophthalmic photographic department, Childrens Hospital Los 

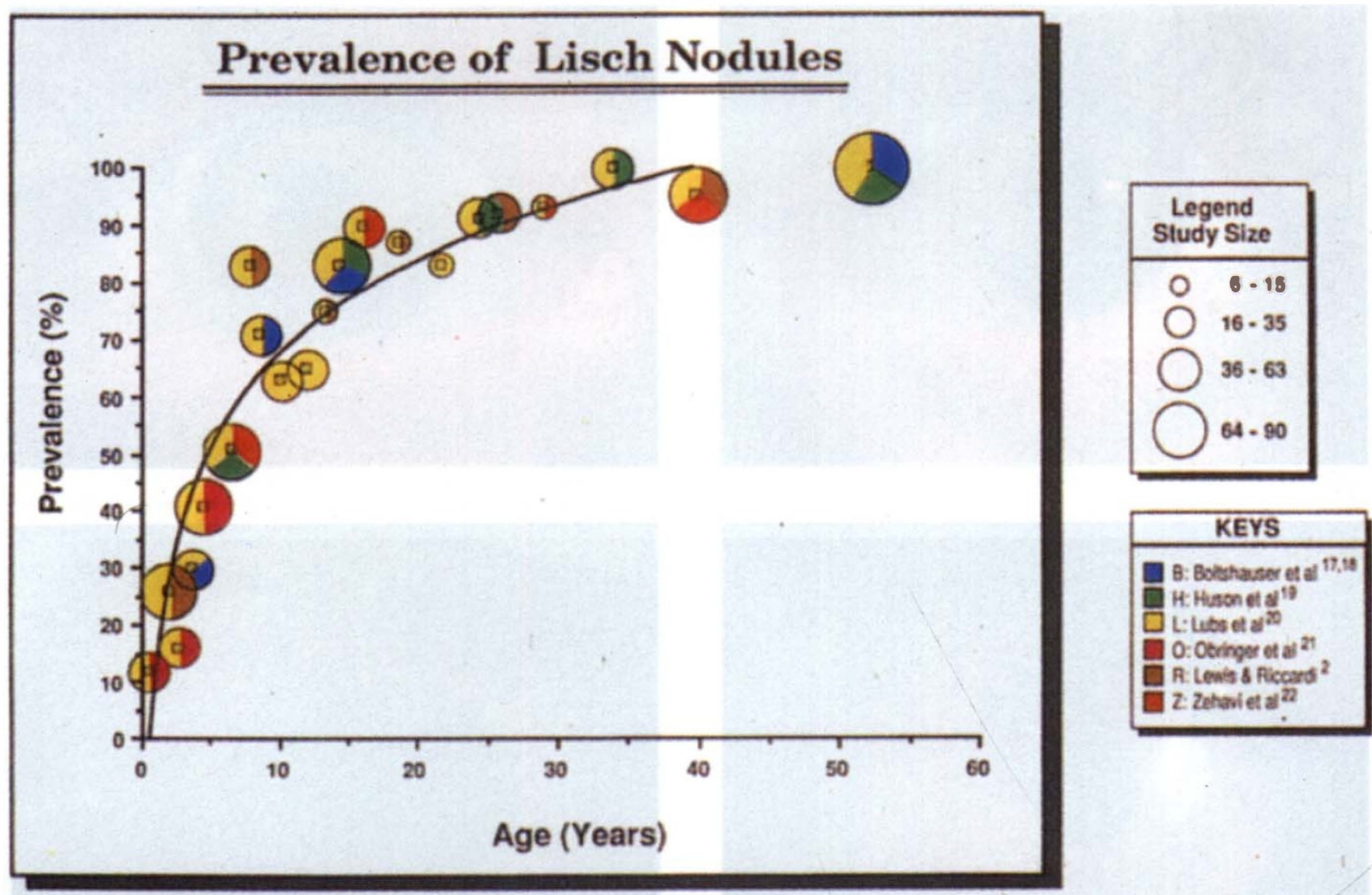

Fig. 5. Graph showing the prevalence of Lisch nodules with age. Diameter of circles represents size of pooled data; colour coding represents studies used to construct that data point.

Angeles, for graphic and photographic skills, and Jonathan Black MA, Los Angeles, for statistical analysis. Jelka G. Orsoni, MD, University of Parma, kindly supplied one of the photographs of Lisch nodules. We also wish to acknowledge the following journals and hospitals for permission to reprint illustrations: Eye, College of Ophthalmologists, England (Fig. 1, left), Acta Soc. Ophthalmol. Jpn. (Fig. 2), Ophthalmologica, Karger, Basel (Fig. 3), Bristol Eye Hospital, UK (Fig. 1, right). Nicola Ragge is a Vista Fellow supported by the Vista Foundation for Blind Children, Los Angeles, California.

Key words: Iris hamartoma, Lisch nodules, Neurofibromatosis type 1, NF1, Ophthalmic manifestations, von Recklinghausen neurofibromatosis.

\section{REFERENCES}

1. Lisch K. Ueber Beteiligung der Augen, insbesondere das Vorkommen von Irisknötchen bei der Neurofibromatose (Recklinghausen). Z Augenheilkd 1937;93:137-43.

2. Lewis RA, Riccardi VM. von Recklinghausen neurofibromatosis. Incidence of iris hamartomata. Ophthalmology 1981;88:348-54.

3. Treacher Collins E. Case of a patient with congenital excess of pigment in the uveal tract and pigmentation of the sclerotic in one eye, which late in life became the seat of a melanotic sarcoma. Trans Ophthalmol Soc UK 1894;14:197-9.

4. Coats G. Unilateral diffuse melanosis of the uvea, with small elevations on the surface of the iris. Trans Ophthalmol Soc UK 1912;32:164-71.

5. Fleischer B. Zwei Fälle von einseitiger Melanosis der Sklera, der Iris und des Augenhintergrundes mit warzenförmigen, kleinen Erhebungen an der Irisvorderfläche. Klin Monatsbl Augenheilkd 1913;51:170-4.
6. Friedenwald H, Friedenwald JS. Melanosis of the lids, conjunctiva and sclera, with wartlike growths on the iris. Arch Ophthalmol 1925;54:51-4.

7. Snell S, Treacher Collins E. Plexiform neuroma (elephantiasis neuromatosis) of temporal region, orbit, eyelid and eyeball. Notes of three cases. Trans Ophthalmol Soc UK 1903;23:157-77.

8. Fuchs E. Naevus pigmentosus und Naevus vasculosus der Iris. Graefes Arch Clin Exp Ophthalmol 1913;86:155-169.

9. Waardenburg PJ. Heterochromie en melanosis. Ned Tijdschr Geneeskd 1918;62:1453-5.

10. Goldstein I, Wexler D. Melanosis uveae and melanoma of the iris in neurofibromatosis (Recklinghausen). Arch Ophthalmol 1930;3:288-96.

11. Gabriélidès C. Fibroneurome orbito-temporo-palpébral (Maladie de Recklinghausen). Ann Ocul 1931;168: 187-206.

12. Kurz J. Tumorbefund in der Iris bei Neurofibromatose. Ofthalm. Sborn 1932;7:294-5. (Abstract in Z Gesamte Ophthalmol 1933;28:566.)

13. Van der Hoeve J. The Doyne Memorial Lecture. Eye symptoms in phakomatoses. Trans Ophthalmol Soc UK 1932;52: $380-401$.

14. Sakurai T. Multiple neurofibroma patient showing multiple flecks on the anterior surface of the iris. Acta Soc Ophthalmol Jpn 1935;39:87-93.

15. Perry HD, Font RL. Iris nodules in von Recklinghausen's neurofibromatosis. Electron microscopic confirmation of their melanocytic origin. Arch Ophthalmol 1982;100: 1635-40.

16. Williamson TH, Garner A, Moore AT. Structure of Lisch nodules in neurofibromatosis type 1. Ophthalmic Paediatr Genet 1991;12:11-17. 
17. Boltshauser E, Flüeler U, Kilchhofer A. Iris hamartomas as diagnostic criterion in neurofibromatosis. Ann Neurol 1985; 18:415-16.

18. Flüeler U, Boltshauser E, Kilchhofer A. Iris hamartomata as diagnostic criterion in neurofibromatosis. Neuropediatrics 1986;17:183-5.

19. Huson S, Harper P, Compston D. Von Recklinghausen neurofibromatosis. A clinical and population study in south-east Wales. Brain 1988;111:1355-81.

20. Lubs M-LE, Bauer MS, Formas ME, Djokic B. Lisch nodules in neurofibromatosis type 1. N Engl J Med 1991;324: 1264-6.

21. Obringer AC, Meadows AT, Zackai EH. The diagnosis of neurofibromatosis- 1 in the child under the age of 6 years. Am J Dis Child 1989;143:717-9.

22. Zehavi C, Romano A, Goodman RM. Iris (Lisch) nodules in neurofibromatosis. Clin Genet 1986;29:51-5.

23. Markowitz JA, Hawkins BS, Diener-West M, Schachat AP. A review of mortality from choroidal melanoma. I. Quality of published reports, 1966-88. Arch Ophthalmol 1992;110: $239-44$.

24. Diener-West M, Hawkins BS, Markowitz JA, Schachat AP. A review of mortality from choroidal melanoma. II. A metaanalysis of 5-year mortality rates following enucleation, 1966 through 1988. Arch Ophthalmol 1992;110:245-50.

25. Toonstra J, Dandrieu MR, Ippel PF, Delleman JW, Rupert Jr
PHJM, Huitema HB. Ȧre Lisch nodules an ocular marker of the neurofibromatosis gene in otherwise unaffected family members? Dermatologica 1987;174:232-5.

26. Ponder B. Neurofibromatosis gene cloned. Nature 1990; 346:703-4.

27. Riccardi VM, Lewis RA. Penetrance of von Recklinghausen neurofibromatosis: a distinction between predecessors and descendants. Am J Hum Genet 1988;42:284-9.

28. Allanson J, Upadhyaya M, Watson G, Partington M, Mackenzie A, Lahey D et al. Watson syndrome-is it a subtype of type-1 neurofibromatosis? J Med Genet 1991;28:752-6.

29. Weleber RG, Zonana J. Iris hamartomas (Lisch nodules) in a case of segmental neurofibromatosis. Am J Ophthalmol 1983;96:740-3

30. Charles SJ, Moore AT, Yates JRW, Ferguson-Smith MA. Lisch nodules in neurofibromatosis type 2. Arch Ophthalmol 1989; 107:1571-2.

31. Garretto NS, Ameriso S, Molina HA, Arberas C, Salvat J, Monteverde D, Sica REP. Type 2 neurofibromatosis with Lisch nodules. Neurofibromatosis 1989;2:315-21.

32. Parry DM, Sherman JL, Pilus A, Kaiser-Kupfer MI, Eldridge R. In: Mulvihill JJ (moderator). Neurofibromatosis 1 (Recklinghausen disease) and neurofibromatosis 2 (bilateral acoustic neurofibromatosis): an update. Ann Intern Med 1990;113:39-52. 